\title{
Common Mental Disorders: socio-demographic and pharmacotherapy profile ${ }^{1}$
}

\author{
Viviane Ferrari Gomes ${ }^{2}$ \\ Tatiana Longo Borges Miguel ${ }^{3}$ \\ Adriana Inocenti Miasso ${ }^{4}$
}

Objective: this study reports an association between Common Mental Disorders and the sociodemographic and pharmacotherapy profiles of 106 patients cared for by a Primary Health Care unit in the interior of São Paulo, Brazil. Method: this is a cross-sectional descriptive exploratory study with a qualitative approach. Structured interviews and validated instruments were used to collect data. The Statistical Package for Social Science was used for analysis. Results: The prevalence of Common Mental Disorders was 50\%. An association was found between Common Mental Disorders and the variables occupation, family income, number of prescribed medications and number of pills taken a day. Greater therapy non-adherence was observed among those who tested positive for Common Mental Disorders. Conclusion: this study's results show the importance of health professionals working in PHC to be able to detect needs of a psychological nature among their patients and to support the implementation of actions to prevent the worsening of Common Mental Disorders.

Descriptors: Mental Disorders; Primary Health Care; Medication Adherence; Mental Health; Drug Utilization.

\footnotetext{
${ }^{1}$ Supported by Conselho Nacional de Desenvolvimento Científico e Tecnológico (CNPq), process \# 478814/2012-7.

2 Undegraduate student in Nursing, Escola de Enfermagem de Ribeirão Preto, Universidade de São Paulo, WHO Collaborating Centre for Nursing Research Development, Ribeirão Preto, SP, Brazil.

${ }^{3}$ Doctoral student, Escola de Enfermagem de Ribeirão Preto, Universidade de São Paulo, WHO Collaborating Centre for Nursing Research Development, Ribeirão Preto, SP, Brazil. Scholarship holder from Coordenação de Aperfeiçoamento de Pessoal de Nível Superior (CAPES).

${ }^{4} \mathrm{PhD}$, Professor, Escola de Enfermagem de Ribeirão Preto, Universidade de São Paulo, WHO Collaborating Centre for Nursing Research Development, Ribeirão Preto, SP, Brazil.
}

Corresponding Author:

Adriana Inocenti Miasso

Universidade de São Paulo. Escola de Enfermagem de Ribeirão Preto

Departamento de Enfermagem Psiquiátrica e Ciências Humanas

Av. Bandeirantes, 3900

Bairro: Monte Alegre

CEP: 14040-902, Ribeirão Preto, SP, Brasil

E-mail: amiasso@eerp.usp.br
Copyright () 2013 Revista Latino-Americana de Enfermagem This is an Open Access article distributed under the terms of the Creative Commons Attribution Non-Commercial License (CC BY-NC).

This license lets others distribute, remix, tweak, and build upon your work non-commercially, and although their new works must also acknowledge you and be non-commercial, they don't have to license their derivative works on the same terms. 


\section{Introduction}

Research has been conducted around the world to assess the occurrence and impact of Common Mental Disorders (CMD). The concept of CMDs characterizes cases that present non-psychotic symptoms, such as insomnia, fatigue, nervousness, headaches, depressive symptoms, irritability, forgetfulness, difficulty concentrating, and non-specific symptoms that lead to functional incapacity but do not meet the requirements of diagnoses listed in the Diagnostic and Statistical Manual of Mental Disorders (DSM-IV) ${ }^{(1)}$.

Nonetheless, the fact these conditions do not fit established diagnostic categories does not relieve the distress of patients, while unnecessary costs increase with referrals and exams, since most professionals usually focus only on the immediate complaint(2). It is also believed that CMDs can lead to high social, economic and individual costs, since such disorders account for one third of the days missed at work and one fifth of all PHC appointments(2).

Among the facts related to the occurrence of CMDs are those associated with worse socioeconomic conditions in many countries(3), including Brazil. Brazilian studies highlight low education, being a female, marital status of being separated or widowed, low income, unemployment, and low social status, living in regions of great socioeconomic inequality, and stress-producing events ${ }^{(2)}$.

Research addressing CMDs in Brazil reveals prevalent rates that vary from $17 \%$ to $35 \%{ }^{(4)}$, and even reach $50 \%{ }^{(5)}$. In addition to a high prevalence in the population and the potential costs related to CMDs, some studies also report an association between CMDs and the use of medication and chronic comorbidities, such as high blood pressure, diabetes, and thyroid diseases ${ }^{(4,6)}$. Even more relevant, a study shows association between CMDs with polypharmacy(7). Hence, the importance of studies characterizing the pharmacotherapy profile of these patients is apparent, seeking their own safety since the concomitant use of various medications may lead to drug interactions and a higher rate of side effects, thus compromising patients' health(6).

Another measure that can support the characterization of aspects related to patient safety concerning the use of medications is medication adherence. In this sense, the literature has shown that the non-adherence of patients with chronic conditions, such as potential comorbidities associated with CMDs, may reach $75 \%$. The reasons for such high levels of medication non-adherence might be related to a lack of understanding on the part of patients that adherence may influence their quality of life and independence in the future ${ }^{(8)}$. It is known that the quantity of pills taken daily may interfere in adherence due to a greater chance of side effects. A study revealed that the risk of nonadherence increases $12 \%$ for each pill taken ${ }^{(9)}$.

Such studies, however, did not investigate the relationship between these variables and CMDs. Therefore, there is a gap in the literature concerning the characterization of the pharmacotherapy profiles of and medication adherence in patients with CMDs. Acquiring knowledge regarding these aspects can support the implementation of health actions directed to this portion of the population designed to improve patient safety in the use of medication. Additionally, such data can contribute to resolvability in the scope of the Brazilian Heath System (SUS) as information can facilitate understanding with greater assertiveness concerning the needs of patients.

Considering the high social, economic and individual costs that may accrue from CMDs as well as the potential indiscriminate use of medication by those afflicted by CMDs, this study objective is to identify the prevalence of CMDs in users of PHC units of a city in the interior of São Paulo, Brazil and the potential association of CMDs with variables inherent to these individuals' socio-demographic and pharmacotherapy profiles.

\section{Method}

This cross-sectional descriptive-exploratory study with a qualitative approach was developed in a PHC unit in a city in the interior of São Paulo, Brazil. It proceeded after approval was obtained from the Institutional Review Board (Protocol 1474/2011) and participants signed free and informed consent forms in accordance with Resolution 196/96, National Health Code. The sample was composed of 106 patients with medical appointments in this PHC unit scheduled, from May to July, 2012. The following equation was used to compute sample size:

$$
n=\frac{z_{\alpha / 2}^{2} P(1-P)}{\varepsilon^{2}},
$$

Where $P$ represents the prevalence of the studied event, $z_{\alpha / 2}$ represents the level of significance adopted and $\varepsilon$ refers to acceptable sampling error. The acceptable sampling error was $5 \%$ and the level of significance was set at $5 \%$. A non-response rate of $15 \%$ was considered. Inclusion criteria were being 18 years old or older, being able to communicate verbally in Portuguese, 
and having an appointment scheduled in the PHC unit (medical or gynecology and obstetric clinics). Exclusion criteria were: attending the service exclusively to use the pharmacy, or for bandages or vaccines (without a medical appointment), being younger than 18 years of age, and being unable to communicate verbally. A pre-test was performed in the study's setting to check whether the instrument's content and form would achieve the proposed objectives. Patients interviewed in the pre-test were not included in the sample.

During data collection, the researchers remained in the research setting every day, for alternate hours, in order to cover the entire unit's office hours. Hence, the patients were approached while they waited for their medical consultations and, if they agreed, interviews were then performed in a private room within the unit itself or their names and addresses were taken to schedule an interview in their homes, if preferred.

A structured interview guided by a script was used to ensure all the participants were asked the same questions. The script contained questions regarding the patients' socio-demographic and pharmacotherapy profile. The participants' medical charts were checked later to correctly identify the prescribed medications and minimize errors.

The description of medications was performed using the first level of the Anatomical Therapeutic Chemical Classification System (ATC) $)^{(10)}$. The validated Brazilian version of the SRQ-20 (Self-Reporting Questionnaire) was used to identify the prevalence of $\mathrm{CMDs}^{(11)}$. The SRQ-20 is a dichotomous scale composed of 20 questions in which each affirmative answer scores one and comprises the total score. Individuals who answer "yes" to eight or more questions are considered to test positive for $\mathrm{CMDs}^{(11-12)}$.

Level of adherence was defined by the application of the Adherence Measure Test $(\mathrm{AMT})^{(13)}$. This test is composed of seven questions. The first is "Have you ever forgotten to take medications?" A Likert scale from 1 to 6 is used for each question. A score of 1 corresponds to "always" (indicating low adherence) and a score of 6 corresponds to "never" (indicating high adherence). The score of each answer is totaled and then divided by the number of questions. Those patients who scored from 1 to 4 on the AMT, that is, checked the answers "always", "almost always", "frequently", and "sometimes," were considered to be non-adherent, while those who scored 5 and 6, which indicate answers "rarely" and "never," respectively, were considered to be adherent.

A qualitative approach was used in the data analysis. Data were analyzed using the Statistical Package for the Social Sciences (SPSS, version 17.0). Statistical associations were found between the study's variables using Fisher's exact test, while the hypothesis of association was accepted when $p$ was equal or below 0.05 .

\section{Results}

\section{Characterization of the study's participants and Common Mental Disorders}

Participants were 106 users of a PHC unit in the interior of São Paulo, Brazil. The sample was mainly composed of women $(88.7 \%)$ while the average age of patients was 40 years old, ranging from 18 to 68 years old. Table 1 shows that half of the interviewed patients $(50 \%)$ tested positive for CMDs. CMDs were associated with the variables occupation $(p<0.01)$ and family income $(p=0.05)$. The prevalence of CMDs was greater among unemployed (64.7\%) and retired (85.7\%) individuals. There was also a trend for CMDs to be associated with level of education $(p=0.06)$.

Table 1 - Prevalence of Common Mental Disorders according to socio-demographic and economic variables. Ribeirão Preto, SP, Brazil, 2012

\begin{tabular}{|c|c|c|c|c|c|c|c|}
\hline \multirow{3}{*}{ Variables } & \multicolumn{4}{|c|}{ Presence of Common Mental Disorders } & \multirow{2}{*}{\multicolumn{2}{|c|}{ Total }} & \multirow{3}{*}{$P$-value } \\
\hline & \multicolumn{2}{|c|}{ No } & \multicolumn{2}{|c|}{ Yes } & & & \\
\hline & $\mathrm{n}$ & $\%$ & $\mathrm{n}$ & $\%$ & $\mathbf{N}$ & $\%$ & \\
\hline Sex & & & & & & & 0,36 \\
\hline Female & 45 & 47.9 & 49 & 52.1 & 94 & 100 & \\
\hline Male & 08 & 66.7 & 04 & 33.3 & 12 & 100 & \\
\hline Age & & & & & & & 0.68 \\
\hline 20 to 30 years & 14 & 60.9 & 09 & 39.1 & 23 & 100 & \\
\hline 31 to 40 years & 16 & 51.6 & 15 & 48.4 & 31 & 100 & \\
\hline 41 to 50 years & 14 & 45.2 & 17 & 54.8 & 31 & 100 & \\
\hline 51 to 60 years & 06 & 50.0 & 06 & 50.0 & 12 & 100 & \\
\hline Above 60 years & 03 & 33.3 & 06 & 66.7 & 09 & 100 & \\
\hline
\end{tabular}


Table 1 - (continuation)

\begin{tabular}{|c|c|c|c|c|c|c|c|}
\hline \multirow{3}{*}{ Variables } & \multicolumn{4}{|c|}{ Presence of Common Mental Disorders } & \multirow{2}{*}{\multicolumn{2}{|c|}{ Total }} & \multirow{3}{*}{$P$-value } \\
\hline & \multicolumn{2}{|c|}{ No } & \multicolumn{2}{|c|}{ Yes } & & & \\
\hline & $\mathbf{n}$ & $\%$ & $\mathbf{n}$ & $\%$ & $\mathbf{N}$ & $\%$ & \\
\hline Education & & & & & & & 0.06 \\
\hline Illiterate & - & - & 01 & 100 & 01 & 100 & \\
\hline $\begin{array}{l}\text { Incomplete primary or secondary } \\
\text { school }\end{array}$ & 15 & 46.9 & 17 & 53.1 & 32 & 100 & \\
\hline Complete secondary school & 10 & 62.5 & 06 & 37.5 & 16 & 100 & \\
\hline Incomplete high school & 06 & 27.3 & 16 & 72.7 & 22 & 100 & \\
\hline Complete high school & 20 & 64.5 & 11 & 35.5 & 31 & 100 & \\
\hline Bachelor's degree & 01 & 100 & - & - & 01 & 100 & \\
\hline Literate & 01 & 33.3 & 02 & 66.7 & 03 & 100 & \\
\hline Marital status & & & & & & & 0.08 \\
\hline Single & 12 & 52.2 & 11 & 47.8 & 23 & 100 & \\
\hline Married & 31 & 62.0 & 19 & 38.0 & 50 & 100 & \\
\hline Widowed & 02 & 22.2 & 07 & 77.8 & 09 & 100 & \\
\hline Cohabitant & 05 & 35.7 & 09 & 64.3 & 14 & 100 & \\
\hline Divorced & 03 & 30.0 & 07 & 70.0 & 10 & 100 & \\
\hline Religion & & & & & & & 0.42 \\
\hline None & 03 & 42.9 & 04 & 57.1 & 07 & 100 & \\
\hline Catholic & 37 & 51.4 & 35 & 48.6 & 72 & 100 & \\
\hline Evangelical & 13 & 54.2 & 11 & 45.8 & 24 & 100 & \\
\hline Other & - & - & 03 & 100 & 03 & 100 & \\
\hline Occupation & & & & & & & $0.01^{*}$ \\
\hline Unemployed & 06 & 35.3 & 11 & 64.7 & 17 & 100 & \\
\hline Irregular informal jobs & 02 & 40.0 & 03 & 60.0 & 05 & 100 & \\
\hline Regular informal jobs & 11 & 40.7 & 16 & 59.3 & 27 & 100 & \\
\hline Regular formal job & 33 & 67.3 & 16 & 32.7 & 49 & 100 & \\
\hline On leave & - & - & 01 & 100 & 01 & 100 & \\
\hline Retired & 01 & 14.3 & 06 & 85.7 & 07 & 100 & \\
\hline Family monthly income & & & & & & & $0.05^{*}$ \\
\hline None & 05 & 71.4 & 02 & 28.6 & 07 & 100 & \\
\hline$\leq 1$ time $\mathrm{MW}$ & 01 & 20.0 & 04 & 80.0 & 05 & 100 & \\
\hline 1-3 times MW & 22 & 40.0 & 33 & 60.0 & 55 & 100 & \\
\hline 3-5 times MW & 19 & 59.4 & 13 & 40.6 & 32 & 100 & \\
\hline$\leq 5$ times $\mathrm{MW}$ & 06 & 85.7 & 01 & 14.3 & 07 & 100 & \\
\hline
\end{tabular}

Minimum Wage $(M W)=R \$ 545.00$ (2011)

$* \mathrm{P} \leq 0.05$ (variables associated with Common Mental Disorders)

\section{Pharmacotherapy Profile and Common Mental Disorders}

In regard to the medications used by the participants (Table 2) that are listed in the Anatomical Therapeutic Chemical Classification System (ATC) adopted by the World Health Organization, the following are usually used for high blood pressure and were present in 25\% of the prescriptions: C09 (Agent acting on the renin-angiotensin system), $\mathrm{C03}$ (Diuretics) and C07A (Beta blocking agents). We note that $12.9 \%$ of the prescriptions were in the N06A classification (antidepressants) and N05B (anxiolytics), while all anxiolytics were benzodiazepines.
The patients testing positive for CMDs comprised the majority of prescriptions, in general. Additionally, an association $(p<0.01)$ between the use of psychotropic medications and CMDs was found. We observed that $90.9 \%$ of Antidepressants (N06A) and $83.3 \%$ of Anxiolytics (N05B) were prescribed for patients who tested positive for CMDs.

Table 3 shows an association between the presence of CMDs and the pharmacotherapy variables "use of medications" $(p=0.05)$, "number of prescribed medications" $(p=0.034)$ and "number of pills taken a day" $(p=0.036)$. 
Table 2 - Distribution of medications used by the study's participants according to the Anatomical Therapeutic Chemical Classification System and the presence of Common Mental Disorders. Ribeirão Preto, SP, Brazil, 2012

\begin{tabular}{|c|c|c|c|c|c|c|}
\hline \multirow{3}{*}{$\begin{array}{l}\text { Anatomical } \\
\text { Therapeutic Chemical Classification System }\end{array}$} & \multicolumn{4}{|c|}{ Common Mental Disorders } & \multirow{2}{*}{\multicolumn{2}{|c|}{ Total }} \\
\hline & \multicolumn{2}{|c|}{ No } & \multicolumn{2}{|c|}{ Yes } & & \\
\hline & $\mathbf{n}$ & $\%$ & $\mathbf{n}$ & $\%$ & $\mathbf{N}$ & $\%$ \\
\hline Drugs for Peptic Ulcer (A02B) & 06 & 14.0 & 11 & 12.4 & 17 & 12.9 \\
\hline Drugs used in diabetes (A10) & 06 & 14.0 & 10 & 11.2 & 16 & 12.1 \\
\hline Agents acting on the renin-angiotensin system (C09) & 05 & 11.6 & 08 & 9.0 & 13 & 9.8 \\
\hline Diuretics (C03) & 04 & 9.3 & 07 & 7.9 & 11 & 8.3 \\
\hline Antidepressants (N06A) & 01 & 2.3 & 10 & 11.2 & 11 & 8.3 \\
\hline Lipid modifying agents (C10A) & 03 & 7.0 & 07 & 7.9 & 10 & 7.6 \\
\hline Beta blocking agents (C07A) & 01 & 2.3 & 08 & 9.0 & 09 & 6.8 \\
\hline Anxiolytics (N05B) & 01 & 2.3 & 05 & 5.6 & 06 & 4.5 \\
\hline Thyroid therapy $(\mathrm{H} 03)$ & 02 & 4.7 & 03 & 3.4 & 05 & 3.8 \\
\hline Others* & 14 & 32.6 & 20 & 22.5 & 34 & 25.8 \\
\hline Total & 43 & 100 & 89 & 100 & 132 & 100 \\
\hline
\end{tabular}

*Insulin, medications for obstructive airway diseases, anti-inflammatory and corticosteroids

Table 3 - Prevalence of Common Mental Disorders according to variables related to the patients' pharmacotherapy profile. Ribeirão Preto, SP, Brazil, 2012

\begin{tabular}{|c|c|c|c|c|c|c|c|}
\hline \multirow{3}{*}{ Variables } & \multicolumn{4}{|c|}{ Presence of Common Mental Disorders } & \multirow{2}{*}{\multicolumn{2}{|c|}{ Total }} & \multirow{3}{*}{$p$-value } \\
\hline & \multicolumn{2}{|c|}{ No } & \multicolumn{2}{|c|}{ Yes } & & & \\
\hline & $\mathrm{n}$ & $\%$ & $\mathbf{n}$ & $\%$ & $\mathbf{N}$ & $\%$ & \\
\hline Use of medications & & & & & & & $0.05^{*}$ \\
\hline Yes & 16 & 37.2 & 27.0 & 62.8 & 43 & 100 & \\
\hline No & 37 & 58.7 & 26.0 & 41.3 & 63 & 100 & \\
\hline Number of types of medications & & & & & & & $0.034^{*}$ \\
\hline Up to 2 & 07 & 31.8 & 15.0 & 68.2 & 22 & 100 & \\
\hline 3 or more & 08 & 38.1 & 13.0 & 61.9 & 21 & 100 & \\
\hline Number of pills a day & & & & & & & $0.036^{*}$ \\
\hline Up to 2 & 05 & 33.3 & 10 & 66.7 & 15 & 100 & \\
\hline 3 or more & 10 & 35.7 & 18 & 64.3 & 28 & 100 & \\
\hline
\end{tabular}

$* \mathrm{p} \leq 0.05$ (variables associated with Common Mental Disorders)

\section{Medication adherence}

In regard to medication adherence, the number of patients who responded to the AMT (48) is greater than the number of patients considered to have used the medications previously described (43). Such a difference is due to the fact that five patients reported the use of ongoing medications and for this reason they answered the AMT. However, their medical files did not list any medications and we opted to use data from the medical files instead in order to minimize errors.

Therefore, $27.1 \%$ of the patients were considered to be non-adherent to medication according to the AMT. Additionally, in regard to the number of types of medications, we observed that patients with more than three types of prescribed medications had a higher percentage of adherence (76.2\%) when compared to those who had up to two types of medications prescribed
$(54.5 \%)$. The same occurred with the number of pills taken a day: greater adherence (78.6\%) was observed among patients taking three or more pills a day, when compared to patients taking up to two pills a day (40\%). Such differences, however, were not found to be significant according to Fisher's test $(p=0.99)$.

The statistical analysis did not show any association between CMDs and medication adherence $(p=0.52)$. Nonetheless, $69 \%$ of the patients who tested positive for CMDs adhered to their medication, while this percentage was higher (78.9\%) among those who tested negative for CMDs.

\section{Discussion}

Analysis of the patients' socio-demographic profiles revealed that most individuals were female. One of the inclusion criteria was having a medical appointment 
in the unit's medical specialties, including gynecologic and obstetrics. Such an aspect might, in part, explain this finding. There are, however, studies showing a greater use of health services by women, as well as an association with $\mathrm{CMDs}^{(5,14-15)}$. Even though there is evidence of a social and biological predisposition in women, given the neuroendocrinological system and social roles, which together increase their susceptibility to these disorders, the potential explanations for an association with sex have yet to be clarified(16). In agreement with this study's findings, there are studies showing no association between sex and $\mathrm{CMDs}^{(2,4)}$. These studies' authors do not explain such findings and suggest that further studies are needed to better understand the relationships between these variables.

As this study shows an association between CMDs and the socio-demographic variables occupation and family income, other studies have attributed the high prevalence of CMDs to indicators that show social disadvantage ${ }^{(15,17)}$. In relation to the association between CMDs and occupation, the literature reveals that unstable labor contracts, low salaries, and a lack of social benefits and labor-rights protection lead to anxiety and depression among informal workers and unemployed individuals ${ }^{(14,17)}$. Obviously, the work situation of individuals influences family income and informal workers or unemployed individuals with a lower family income are more subject to CMDs ${ }^{(14)}$. Such considerations may, in part, explain this study's findings concerning occupation and income.

In regard to education, the study's results reinforce previous data showing an association between a low level of education and CMDs. Education improves an individual's chances of having better life opportunities, in addition to influencing one's aspirations, self-esteem and the acquisition of knowledge, which in turn may motivate attitude and behavior. Lack of education may be related to a lower level of decision-making power, leading to a relative incapacity to influence one's environment and, consequently, harm one's psychological health ${ }^{(2,14)}$.

Given the knowledge that a socio-demographic profile that indicates social disadvantage is strongly associated with CMDs in the scope of PHC, which is the object of this study, there is a need for strategies and to train professionals who provide care to this population. The current Brazilian Mental Health Policy provides the inclusion of mental health actions in this scope. It also suggests the implementation of some of these actions, such as Matrix Support. However, such actions are absent in most of these services, despite the high prevalence of
CMDs reported in the literature ${ }^{(4-5)}$ and in this study. The professionals' lack of training is an obstacle because, in addition to many professionals being incapable of detecting signs of mental disorders, they do not believe that mental health is a responsibility of $\mathrm{PHC}^{(18-19)}$. In this context, PHC nurses play an important role in adapting mental health actions to patients who present social disadvantage since these professionals know the realities of patients and can facilitate the supply of integral care.

Considering the study's objectives and its relevance for clinical practice, the fact that half of the interviewed patients have presented CMDs draws attention. Even though this percentage is in agreement with the literature showing that the world prevalence of CMDs ranges from $22.7 \%$ to $50.3 \%{ }^{(4-6,17,20)}$, it is a concern given its considerable impact on care provided within the scope of PHC. In agreement with the literature, this study's results reveal an association between CMDs and the use of psychotropic medications. The rate of use of psychotropic medications observed in this study (12.9\%) was similar to that observed in the population in general, which is estimated to be from $9 \%$ to $13 \%{ }^{(15)}$. If, however, we consider the number of patients who tested positive for CMDs, we can infer that a large number of them do not receive mental health treatment, even though they need such treatment. These aspects show the need to devise new strategies to approach this issue in the health services, considering the representations of the disease in specific groups, which may be different from those that ground the knowledge of modern physicians, which is focused on the mind and body dichotomy, and value both attentive listening and properly receiving patients within the health system ${ }^{(1,19,21)}$.

We note that the symptomatology presented by these patients are frequently identified by the health system as symptomatic of distress, in agreement with the current biological model, in which it is more acceptable that people complain of organic diseases or physiological alterations, because these are more "objective"(21). As a consequence, because these patients do not have their complaints properly addressed, they may return to the service many times, overloading the system and increasing costs with unnecessary exams and medication.

The findings concerning the use of medication corroborate this conclusion since data concerning the patients' pharmacotherapy profile show an association between CMDs and the use of medication, the number of prescribed medications and the number of pills taken daily. The percentage of patients who use more than two 
types of medications a day and more than two pills a day is greater among those who tested positive for CMDs, which is in agreement with a previous study that also found associations between CMDs and polypharmacotherapy ${ }^{(4)}$. This is a concern since polypharmacotherapy poses severe health risks as it increases the chances of drug interactions and side effects.

The association between CMDs and the use of medication was also found in a study in which individuals with CMDs were twice as likely to use medication when compared to individuals without CMDs. This same study also revealed an association between CMDs and clinical comorbidities. Even though that variable was not investigated in this study, a high number of medications were prescribed for organic pathologies. According to the ATC classification shown in Table 2, the most prevalent class of medication was that for blood pressure followed by medications for peptic ulcers and diabetes.

In relation to medication adherence, we found that $27.1 \%$ of the patients were identified as nonadherent. Considering the types of the most prescribed medications in this study, we observe that the rate of adherence found is in agreement with the literature, in which adherence to diabetes and high blood pressure medication ranges from $36 \%$ to $66 \%^{(22-23)}$.

Although statistical association between CMDs and therapy adherence has not been shown, a lower level of adherence was observed among those with CMDs. As previously mentioned, it is known that the number of medications, along with the number of pills, taken daily interferes with therapy adherence ${ }^{(9,15)}$. In this regard, one study ${ }^{(24)}$ revealed that the use of multiple medications exposes the patient to more complex treatment that requires more attention, memory and organization in order to deal with the times the medication are administered.

As observed in previous studies ${ }^{(5-6)}$, this study's findings corroborate the idea that even though CMDs are prevalent, they are not identified by health professionals, the evidence for which is the large number of medications related to organic complaints prescribed to patients with CMDs.

We note that the issue is not about encouraging the use of psychotropic medications, but taking into consideration that these patients do not have their needs addressed in an integral fashion. From this perspective, it is relevant to consider that the comorbidities usually associated with CMDs are closely related to individuals' psychological spheres, which in turn is related to the safe use of medications.
Considering the impact CMDs may have on PHC, there is a need to implement strategies in healthcare addressing the psychological sphere of patients since this study provides results showing greater risks related to the use of medications among patients who tested positive for CMDs. The literature on this topic reports Community Therapy in PHC as a possible way to provide care in situations of distress through attentive listening, strengthening social support networks and the discussion of the issues of collective interest ${ }^{(1)}$. There is evidence that health technologies, such as the use of telephones, can strengthen bonds between professionals and patients, as well as encourage therapy adherence $^{(25)}$. Another strategy is the supply of group care using techniques such as psychoeducation or group therapy(26).

Since studies on this topic indicate that there is a strong relationship between CMDs and psychosocial issues, as opposed to the professionals' attitude of being prone to medicate; the actions of health professionals should take into account the cultural codes of individuals cared for in PHC, who are usually labeled as "polycomplainers", "psychosomatic" or "hysterical"(1). In addition to the challenge of properly addressing these patients, the competence and technical qualification of professionals should be taken into account since PHC units are staffed with general medical practitioners, which may hinder the identification of $\mathrm{CMDs}^{(2)}$.

Because this is a cross-sectional study, causal relationships cannot be established among the observed associations. However, the theory of stressproducing events and the theory of social roles and social support have been established for years as explanations for socioeconomic indicators and $\mathrm{CMDS}^{(27)}$. Another limitation of this study is the use of a screening instrument to establish the prevalence of CMDs instead of the gold standard of psychiatric interviews. Such a potential drawback, however, is resolved by SRQ-20 validation studies that compare the instrument to the gold standard, confirming the cut off point adopted in this study ${ }^{(12)}$.

\section{Conclusions}

The association of CMDs with socioeconomic variables reaffirms the view that the presence of these disorders is strongly linked to social disadvantage. Also, the results of this study reveal a sample of patients with a high prevalence of CMDs and a high level of use of medication and also the unsafe use of medications, 
given the association of CMDs and pharmacotherapy variables with lower therapy adherence among patients with CMDs.

We note that a large part of the medications prescribed are for organic diseases, thus patients do not receive care appropriate to their profiles, which also include complaints of a psychological order. From this perspective, this study's results show the importance of health professionals working in $\mathrm{PHC}$ being prepared to detect psychological complaints among the population to which they provide care. It is also necessary to reflect upon the education of health professional in the psychiatric field who are usually found only in specialized services, which may hinder the adoption of the biopsychosocial health concept in clinical practice.

Further research, especially population-based longitudinal studies, is needed to better understand the associations found and provide insights that strengthen mental health care within the PHC sphere.

\section{References}

1. Fonseca MLG, Guimarães MBL, Vasconcelos EM. Sofrimento difuso e transtornos mentais comuns: uma revisão bibliográfica. Rev APS. 2008;11(3):285-94.

2. Fortes $S$, Villano LAB, Lopes CS. Nosological profile and prevalence of common mental disorders of patients seen at the Family Health Program (FHP) units in Petrópolis, Rio de Janeiro. Rev Bras Psiquiatr. 2008;30(1):32-7.

3. Marín-Léon L, Oliveira HB, Barros MB, Dalgalarrondo $\mathrm{P}$, Botega NJ. Social inequality and common mental disorders. Rev Bras Psiquiatr. 2007;29(3):250-3.

4. Coelho FMC, Pinheiro RT, Horta BL, Magalhães PVS, Garcias CMM, Silva CV. Common mental disorders and chronic non-communicable diseases in adults: a population-based study. Cad Saúde Pública. 2009;25(1):59-67.

5. Fortes S, Lopes CL, Villano LAB, Campos MR, Gonçalves DA, Mari JJ. Common mental disorders in Petrópolis-RJ: a challenge to integrate mental health into primary care strategies. Rev Bras Psiquiatr. 2011;33(2):150-6.

6. Aikens JE, Perkins DW, Lipton B, Piette JD. Longitudinal analysis of depressive symptoms and glycemic control in type 2 diabetes. Diabetes Care. 2009;32:1177-81.

7. Moreira JKP, Bandeira M, Cardoso CS, Scalon JDS. Prevalência de transtornos mentais comuns e fatores associados em uma população assistida por equipes do Programa Saúde da Família. J Bras Psiquiatr. 2011;60(3):221-6.
8. Araújo MFM, Freitas RWJ, Fragoso LVC, Araújo TM, Damasceno MMC, Zanetti ML. Cumprimento da terapia com antidiabéticos orais em usuários da atenção primária. Texto Contexto Enferm. 2011;20(1):135-43.

9. Colombrini MRC, Lopes MHBM, Figueiredo RM. Adesão à terapia antiretroviral para HIV/Aids. Rev Esc Enferm USP. 2006;40(4):576-81.

10.World Health Organization. ATT/DDD Index 2009 [Internet] [acesso 27 abr 2011]; Disponível em: http:// www.whocc.no/atcddd/indexdatabase.

11. Mari JJ. Williams PA. Validity study of a Psychiatric Screening Questionnaire (SRQ-20) in Primary care in the city of São Paulo. Br J Psychiatry. 1986;148(1):23-6. 12. Goncalves DM, Stein AT, Kapczinski F. Avaliação de desempenho do Self-Reporting Questionnaire como instrumento de rastreamento psiquiátrico: um estudo comparativo com o Structured Clinical Interview for DSM-IV-TR. Cad Saúde Pública. 2008;24(2):380-90.

13. Delgado $A B$, Lima $M L$. Contributo para a validação concorrente de uma medida de adesão aos tratamentos. Psicol Saúde \& Doenças. 2001;2(2):81-100.

14. Ludemir AB, Melo DA Filho. Condições de vida e estrutura ocupacional associadas a transtornos mentais comuns. Rev Saúde Pública. 2002;36(2):213-21.

15. Lima MCP, Menezes PR, Carandina L, Cesar CLG, Barros MBA, Goldbaum M. Transtornos mentais comuns e uso de psicofármacos: impacto das condições socioeconômicas. Rev Saúde Pública. 2008;42(4):717-23.

16. King $\mathrm{SL}$, Hegadoren KM. An integrative science approach: value added in stress research. Nurs Health Sci. 2006;8(2):114-9.

17. Costa AG, Ludermir AB. Transtornos mentais comuns e apoio social: estudo em comunidade rural da Zona da Mata de Pernambuco, Brasil. Cad Saúde Pública. 2005;21:73-9.

18. Silva MCF, Furegato ARF, Costa ML Júnior. Depression: viewpoints and knowledge of nurses from the basic health network. Rev. Latino-Am. Enfermagem. 2003;11(1):7-13.

19. Matumoto M, Vieira KCS, Pereira MJB, Santos $\mathrm{CB}$, Fortuna CM, Mishima SM. Production of nursing care in primary health care services. Rev. Latino-Am. Enfermagem. 2012;20(4):710-7.

20. Gholoum S, Bener A, Abou-Saleh MT. Prevalence of mental disorders in adult population attending primary health care setting in Qatari population. J Pak Med Assoc. 2011;61(3):216-21.

21. Azevedo LFM. Um estudo sobre a "Doença dos Nervos" para além de um sofrimento incorporado. Rev Interinst Psicol. 2012;5(2):223-35. 
22. Irvin MR, Shimbo D, Mann DM, Reynolds K, KrouselWood M, Limdi NA, et al. Prevalence and correlates of low medication adherence in apparent treatment-resistant hypertension. J Clin Hypertens. 2012;14(10):694-700.

23. Gomes-Villas Boas LC, Foss MC, Freitas MCF, Pace AE. Relationship among social support, treatment adherence and metabolic control of diabetes mellitus patients. Rev. Latino-Am. Enfermagem. 2012;20(1):52-8.

24. Rocha $\mathrm{CH}$, Oliveira APS, Ferreira C, Faggiani FT, Schtoeter G, Souza ACA et al. Adesão à prescrição médica em idosos de Porto Alegre, RS. Ciênc Saúde Coletiva. 2008;13(Sup):703-10.

25. Zanetti ML. Chronic non-communicable diseases and health technologies [Editorial]. Rev. Latino-Am. Enfermagem. mai-jun 2011;19(3):449-50.

26. Souza AMA, Fraga MNO, Moraes LMP, Garcia MLP, Moura KDR, Almeida PC, Moura EMV. Grupo terapêutico: sistematização da assistência de enfermagem em saúde mental. Texto Contexto Enferm. 2004;13(4):625-32.

27. Gonçalves DM, Stein AT, Kapczinski F. Transtornos mentais comuns em comunidade atendida pelo Programa Saúde da Família. Cad Saúde Pública. 2008;24(2):380-90. 